\begin{abstract}
Article
Darren G. Lilleker | Duje Bonacci

The structure of political e-expression

\section{The structure of political e-expression: What the Brexit}

\section{campaign can teach us about political talk on Facebook}

Darren G. Lilleker

Bournemouth University

Dr Darren G. Lilleker is associate professor in political communication in the Faculty of Media and Communication, Bournemouth University, United Kingdom. Dr Lilleker’s expertise is in public engagement in politics, and in particular how public engagement can be potentiated and facilitated using technological innovations. Dr Lilleker has published widely on the professionalization and marketization of political communication including the textbook Key Concepts in Political Communication (Sage, 2006), and Political Communication and Cognition (Palgrave (2014), Political Campaigning, Elections and the Internet (Routledge, 2011) and has co-edited The Marketing of Political Parties (MUP, 2006), and Political Marketing in Comparative Perspective (MUP, 2005).

Contact: Faculty of Media and Communication, Bournemouth University, Fern Barrow, Poole BH12 5BB, United Kingdom.

E-mail: dlilleker@bournemouth.ac.uk

Duje Bonacci 


\title{
University of Zagreb
}

Duje Bonacci holds M.Sc. degrees in Atomic and Molecular Physics and Astrophysics from University of Zagreb and Communicating Science from University of Cardiff. He started his career as a research student in theoretical physics and then shifted to professional practice of public relations. He was the first head of the Public Relations Office of the Ruđer Bošković Institute in Zagreb, Croatia, and a spokesman for the Ministry of Science, Education and Sports of the Republic of Croatia. He published scientific papers in the field of atomic and molecular physics, communicology and most recently in the areas of political communication and media research. He is a lecturer in the fields of social studies of science and technology and public relations at the Centre for Croatian Studies, University of Zagreb. He is founder of VoxPopuli, a start-up company developing a tool for real-time public opinion monitoring.

Contact: Centre for Croatian Studies, University of Zagreb, Zagreb, Croatia.

E-mail: dbonacci@voxpopuli.hr

\begin{abstract}
Social media represents a space where the more politically engaged can commune around issues and events of importance and exchange views. Often the spaces created, especially when hosted by a partisan or campaign organization, tend to be ideologically homogenous eschewing debate or critique. The UK's referendum on EU membership represents an opportunity to explore how citizens use social media, in this case Facebook, to express their political views in relation to a controversial and polarizing issue of significant national importance. The data extracted from the public pages of the four most important Leave and Remain campaigns are used to explore the strategies of Leave and
\end{abstract}


Remain campaigns as well as the reactions of subscribers. The data show the Leave campaign the most proactive posters, creating more engaging content and, in turn, gaining an advantage in terms of visibility online. Leave supporters were also more prone to act as cheerleaders for the campaign applauding attacks on Remain leaders and spokespeople and promoting campaign slogans. Remain subscribers similarly endorsed negative messages but were keener to debate the detail behind slogans and critique the official campaign strategy and messaging. Endogenous factors relating to the demographic of the supporter groups and the campaign messages, as well as exogenous factors relating to the social norms of behaviour with the pages, are discussed as explanatory factors for the different dynamics observed. Notwithstanding the limitations of big data discourse analysis, we thus suggest the Facebook communities around each campaign page can be seen as microcosms of wider supporter groups and thus we propose that analysis of discourse within social media platforms such as Facebook allow better understanding of wider societal engagement with political communication and the dynamics of contestation that exist around political issues and events.

Keywords:

political discourse

public attitudes

big data

Facebook

social media

Campaigns

referenda 
Brexit

\section{Introduction}

The mediation of politics has long been argued to stimulate interest, engagement and discussion (Graber 2003). Within social media environments, these processes can be almost instantaneous. Accidental exposure to a political message can grab users’ interest and lead to further actions including liking, sharing and commenting (Koc-Michalska et al. 2016). Political campaigns therefore attempt to produce content that can stimulate interest as well as creating pages that can be liked, so building a supportive community around an organization or specific campaign. Supportive communities are particularly useful as they provide free labour to the campaign, individuals willing to like and share content and so extend the reach of a particular message within online networks. Theoretically, a campaign's page should operate like an echo chamber; the community will be ideologically homogenous and their actions and comments will be supportive and positive (Wojcieszak and Mutz 2009). However much of the commenting found on social media pages and platforms is what has been referred to e-expressive behaviour, individuals voicing their opinions and concerns about issues that matter to them, and responding to other commenter’s (Gibson and Cantijoch 2013). Thus, campaign pages might have a more heterogeneous character. This research explores the nature and character of user discourse in response to the Facebook posts of the main campaigns on either side of the UK referendum on EU membership. The highly divisive and contentious topic allows an insight into the dynamics of social media users' engagement with politics, and the extent social media can be viewed as a space for open discussion or homogenous cheerleading. 


\section{Research context}

The United Kingdom's referendum on membership of the European Union offered citizens a choice on one of the most important decisions of their lifetime, expectedly the campaign proved to be highly divisive as well as emotionally and politically charged. Media coverage and opinion pollsters consistently showed the nation was polarized (Goodwin and Heath 2016a), with those referred to by the epithets Remainers and Brexiteers pitted against one another. The campaign appeared to increase polarization (Bogdanor 2016), but were these two groups as distinct as media reporting suggests. One way of understanding the attitudinal and communication dynamics of these groups is through an examination of public contributions to the campaign on Facebook. We suggest that social media can be viewed as a microcosm of society. The users who discuss politics maybe the most engaged, and so unrepresentative of the broader population, but they express views that are likely shared by a wider group of citizens (Anstead and O'Loughlin 2015). In particular, the extent to which users express their views with passion and consistency and demonstrate high engagement can be indicative of the trends in and strength of attitudes relatively (Ceron et al. 2014), a phenomenon evidenced when comparing partisan commitment online during the 2015 United Kingdom general election (Lilleker and Jackson 2017).

\section{E-expression and political discourse on social media}

While the mediation of politics has long been suggested to provide pathways to greater levels of political engagement (Graber 2003), such arguments have recently focused on the affordances offered by digital technologies and in particular social media. Social media is argued to operate as a third space (Graham et al. 2015; Wright et al. 2016), 
where discussion can take place that bridges social and ideological divides and where citizens can discuss important issues of the day, find common ground, debate and develop an understanding of differing viewpoints (Routledge, 1996). Although conversations can be symmetrical, it is more likely for them to be asymmetrical and fragmented over time (Gunitsky 2015). Users can enter into intense conversations or post graffiti-style comments (Jackson and Lilleker 2009); but both represent expressive behaviour (Gibson and Cantijoch 2013), the voicing of attitudes and opinions that may be representative of broader attitudinal trends (Ceron et al. 2014).

The patterns of behaviour can take place with open forums designed to be apolitical (Jackson et al. 2013) as well as more partisan or less ideologically heterogeneous communities. Research shows politically engaged Facebook users have a greater tendency to form or join communities that are ideologically homogenous, focused on a single perspective towards an issue or support for one party or organization (Wojcieszak and Mutz 2009). This behaviour is encouraged by political organizations. Organizations create bespoke pages, publicize them in order to build a community and then persuade that community to become more active (Jackson and Lilleker 2009). While these organization-oriented spaces fail to meet the criteria of third space public spheres, they may resemble in character the offline spaces where political talk occurs (Papacharissi 2002). In everyday, offline, life, people similarly have a tendency to talk politics with the like-minded, and when not they eschew politics altogether, and therefore the more homogenous online communities may represent microcosms of society (Anstead and O'Loughlin 2015). This hypothesis suggests social media discussions present opportunities to garner insights about wider public attitudes, while studying the 
patterns of discourse can also teach us about the factors that shape the dynamics of online interactions.

Exploring user discourse dynamics within spaces created by a campaign can also allow an understanding of how political communication stimulates e-expression. Politics remains a minority interest; interest can increase during contentious events and users can engage in a variety of forms of activity depending on their commitment (Warren \& Gaskill. 2015). The host communication strategy and behaviour of other users within communities may incentivize or disincentivize starting or joining conversations (Zhu et al. 2017). Some users are incentivized sufficiently by the fact that Facebook offers a space for self-expression (Vraga et al. 2015), and their self-efficacy can be increased if they receive positive feedback on their contributions (Lilleker and Koc-Michalska 2017). Thus, users will perform in ways likely to maximize positive feedback, in particular when sharing content or offering opinions; these community dynamics therefore might perform in the same way as any communicative space. Vocal contributors may make controversial statements to get a response or make statements that everyone in the community agrees with in order to gain acceptance. But, at least in theory, the choice of communication will depend on the individual as well as the communication dynamic of the community (Zhu et al. 2017). We explore the agendas of pages created by the Leave and Remain campaigns during the 2016 UK EU membership referendum in order to explore if communities that represent socio-political polar opposites do indeed demonstrate unique communicative characteristics that validates the view that these represent societal microcosms while also reaching some conclusions regarding the dynamics of the campaigns and their supporter communities. 
The key questions posed in this article are as follows:

1. What were the communication dynamics within the specific spaces during the course of the campaign?

2. What are the communicational drivers of engagement, can patterns of actions (Likes and Shares) and interactions (Comments and Conversations) be attributed to communicative strategies or agendas?

3. Were the communities homogenous; or is there evidence of pluralist debating, diversity or challenges made to the ideational hegemony?

\section{Methodology}

Data were captured from the Facebook pages of four organizations: the two official Campaigns, LeaveEU and StrongerIN, as well as two unofficial but reasonably large competitors, Lets Stay In Europe (LetsStayIn) and VoteLeave. The data corpus constitutes all posts made to the page by the host, the numbers of likes, shares and comments (first order direct to the page and second order on shared versions of a post), as well as all the text comments by visitors to those pages. The data were scraped from each page using a version of the Vox Populi harvester (Bonacci et al. 2016), adapted for harvesting Facebook data. The data were exported into Microsoft Excel as a file including all text as well as the date stamp and details of user reactions.

Analysis involved quantitative and qualitative dimensions. The text data from posts and comments were coded by words used, with words being attributed to particular communication strategies and policy areas. Samples of posts using popular terms were selected to ensure that the context of word use was understood. For example, the appearance of the word jobs in posts or comments usually related to economic arguments 
for remaining or leaving the European Union (EU), similarly words such as astonishing and ghastly were used to challenge opposition claims and blame opponents for exaggerating or lying. The categorizations we developed by looking qualitatively at the posts and gaining an understanding of how the campaigns utilized language allowed us to identify four policy areas (economy, sovereignty, immigration and cooperation (security and the environment)); two persuasive devises (personalization, referencing individual names; and the attribution of blame, using pejorative language against a group or individual) and finally campaigning posts regarding events or requests to contribute. The categorization cannot capture every post but, due to the size of the corpus of data, analysis provides indications on which broader assumptions can be based (Jungherr 2015). The posts captured from each campaign number 78\% (LetsStayIn), 65\% (LeaveEU), 64\% (VoteLeave) and 52\% (StrongerIN).

To overcome the major flaw with big data studies, the inability to test assumptions drawn from automated categorizations of a large body of text, we conducted qualitative analysis involving reading and understanding selected posts that attracted intense discussion (multiple comments by groups of users) as well as posts that attracted only single comments by multiple users. Posts were selected purposefully (as above) as well as through random sampling in order to validate the assumptions underpinning the quantitative coding of words and categorization of posts (Laver et al. 2003). The qualitative analysis permitted us to identify key examples of dynamics and common phenomena that cannot be reliably identified using text analysis programmes (Angus et al. 2013). The qualitative observations are also used to provide examples of campaign 
communication strategies as well as the kinds of responses that posts of a certain type or topic were likely to elicit.

\section{Mapping the communities}

Prior to focusing in-depth on the analysis of the discourse strategies found in host posts and user comments, it is instructive to offer a general description of the levels of interactivity on these pages. Table 1 and Figure 1 demonstrate that the more proactive a campaign is in generating content the greater responses it earns from the community. Stronger In and Lets Stay In seemed to demonstrate an element of complacency in the campaign; they created their profiles later and then posted less which correlate with having a less active following. Follower activity might however also be an indicator of their enthusiasm, a point we will revisit when focusing on their commenting behaviour. In contrast to the sites promoting the Remain side, the LeaveEU campaign was exponentially most proactive; the campaign was very active as soon as the referendum was officially put before parliament, maintained its communicative advantage in every month except May and continued as a hub of commentary even after the result was announced. 
Table 1: Activities on Facebook pages by hosts and visitors

\begin{tabular}{|c|c|c|c|c|c|c|c|c|}
\hline Campaign & LeaveEU & & VoteLeave & & StrongerIn & & $\overline{\text { LetsStayInEu }}$ & \\
\hline Period & $\begin{array}{l}\text { 1 September } \\
2015-1 \\
\text { September } \\
2016\end{array}$ & $\begin{array}{l}1 / 2-23 \text { June } \\
2016\end{array}$ & $\begin{array}{l}\text { 1 September } \\
2015-1 \\
\text { September } \\
2016\end{array}$ & $\begin{array}{l}1 / 2-23 \text { June } \\
2016\end{array}$ & $\begin{array}{l}\text { 1 September } \\
2015-1 \\
\text { September } \\
2016\end{array}$ & $\begin{array}{l}\text { 1/2-23 June } \\
2016\end{array}$ & $\begin{array}{l}\text { 1 September } \\
\text { 2015-1 } \\
\text { September } \\
2016\end{array}$ & $\begin{array}{l}\text { 1/2-23 June } \\
2016\end{array}$ \\
\hline (1) Total posts published & 1813 & 896 & 939 & 769 & 590 & 393 & 51 & 29 \\
\hline (2) Total posts reacted to & 1806 & 891 & 923 & 767 & 590 & 393 & 51 & 29 \\
\hline (3) $\%$ of posts reacted to (2)/(1) & 99.6 & 99.4 & 98.3 & 99.7 & 100.0 & 100.0 & 100.0 & 100.0 \\
\hline (4) Total reactions & $8,704,358$ & $5,864,885$ & $4,533,944$ & $4,401,208$ & $2,306,707$ & $2,110,327$ & 3391 & 3121 \\
\hline (5) Average reactions per post reacted to (4)/(2) & 4820 & 6582 & 4912 & 5738 & 3910 & 5370 & 66 & 108 \\
\hline (6) Total reacting visitors & 689,773 & 570,624 & 501,152 & 496,164 & 583,678 & 565,654 & 1427 & 1396 \\
\hline (7) Average reactions per reacting visitor (4)/(6) & 12.6 & 10.3 & 9.0 & 8.9 & 4.0 & 3.7 & 2.4 & 2.2 \\
\hline (8) Total posts shared & 1775 & 872 & 822 & 672 & 585 & 391 & 49 & 28 \\
\hline (9) \% of posts shared (8)/(1) & 97.9 & 97.3 & 87.5 & 87.4 & 99.2 & 99.5 & 96.1 & 96.6 \\
\hline (10) Total shares & $4,890,815$ & $3,799,004$ & $2,549,881$ & $2,510,368$ & $1,290,009$ & $1,217,761$ & 1694 & 1549 \\
\hline (11) Average shares per shared post (10)/(8) & 2755.4 & 4356.7 & 3102.0 & 3735.7 & 2205.1 & 3114.5 & 34.6 & 55.3 \\
\hline (12) Total posts commented on & 1806 & 891 & 813 & 668 & 590 & 393 & 51 & 29 \\
\hline (13) \% of posts commented on (12)/(1) & 99.6 & 99.4 & 86.6 & 86.9 & 100.0 & 100.0 & 100.0 & 100.0 \\
\hline (14) Total comments & $1,164,061$ & 718,730 & 483,710 & 466,689 & 941,928 & 778,472 & 2168 & 1770 \\
\hline $\begin{array}{l}\text { (15) Average comments per post commented on } \\
(14) /(12)\end{array}$ & 645 & 807 & 595 & 699 & 1596 & 1981 & 43 & 61 \\
\hline (16) Total commentators & 208,063 & 152,133 & 121,950 & 119,432 & 132,683 & 121,783 & 564 & 475 \\
\hline (17) Average comments per commentator (14)/(16) & 5.6 & 4.7 & 4.0 & 3.9 & 7.1 & 6.4 & 3.8 & 3.7 \\
\hline (18) Average commentators per post commented on & 493 & 612 & 440 & 519 & 702 & 911 & 23 & 32 \\
\hline $\begin{array}{l}\text { (18) Average comments per commentator per post } \\
\text { commented on }(14) /\left((12)^{*}(16)\right)\end{array}$ & 0.0031 & 0.0053 & 0.0049 & 0.0058 & 0.0120 & 0.0163 & 0.0754 & 0.1285 \\
\hline
\end{tabular}

Figure 1: Posts by month per campaign profile between September 2015 and September 2016. 
The Leave campaign sites also posted most visual material, which is found to be more engaging and shareable (Cvijikj and Michahelles 2013). Figure 2 shows that LeaveEU posted exponentially greater numbers of photos and videos, and within June, the two Leave campaigns posted 320 photos and 229 videos between them compared to 30 and 62, respectively, for Remain. The LeaveEU site also referenced the mainstream media using hyperlinks, sometimes to reinforce their arguments, at other points to criticize opponents, a strategy also followed by LetsStayIn. While links to media coverage featured in StrongerIn posts, the overwhelming majority of hyperlinking was to their own website suggesting their strategy was to direct their Facebook subscribers to their main campaign hub. StrongerIn also posted text-heavy expert testimony. Thus, based on previous analysis of social media behaviour, although from a corporate communication context, the pro-Leave campaigns produced a significantly greater number of posts that prove most likely to receive the likes and shares that extend the network reach of a message (Cvijikj and Michahelles 2013). This general norm of online behaviour seems vindicated in this context by the numbers of reactions received overall and per post.

Figure 2: Posts by month by post type per campaign profile within the campaign period 23 January-23 June 2016.

The differences in the vibrancy of the communities are marked. Although the average number of comments per post was higher for StrongerIn (see Figure 3), the LeaveEU campaign attracted slightly more comments overall as well as attracting a higher number of individual commenters. So those active on the 'Remain' pages were 
smaller in number but proved more frequent in utilizing the affordances for expressing their views. Leave attracted a larger group of subscribers who commented less frequently. Figure 3: Distinct commentators by month per campaign profile between September 2015 and September 2016.

Combining community activity data for each side, it is clear the two Leave campaign sites gained the greatest traction, between them gaining double the amount of shares in May and a third more in June at the height of the campaign. While Vote Leave complemented and at points equalled the support enjoyed by the official LeaveEU page, LetsStayIn did not offer a bolster to the Remain cause. Therefore, while StrongerIn did not lag far behind in the crucial June month, LeaveEU gained traction early and when combined with the more controversial Vote Leave this side had a clear advantage in being made more visible through having a more active followership. Therefore, more non-engaged Facebook users may have been accidentally exposed to pro-Leave material if they were connected to the networks of subscribers to their pages. Furthermore, given the more engaging nature of the material, pro-Leave arguments may have framed some debates through their online advertising strategy (Campbell and Lee 2016) building an atmosphere favourable to the pro-Leave argument. StrongerIn content appears to have proved less attractive to supporters, and so was not promoted as much, suggesting either they did not want to associate themselves with the content to the same extent as proLeave supporters or they were insufficiently committed to actively push campaign content.

\section{Divergent agendas: Divergent conversations}


The number of comments received map onto the level of proactivity of each campaign page, but crucially within the final month of the campaign, June 2016, there is greater parity (see Figure 3). However, when analysing the nature of comments, there are marked differences in the agendas of commenters, how they map on the overall campaign agendas, and the nature of the comments themselves.

Firstly we focus on whether comments were made directly to posts or to the shared variants. One might hypothesize that first-order comments, from the community of individuals liking a page, are more likely to be supportive than second-order comments from people who do not like the page. This is particularly the case as first-order comments, made directly to the post on the campaign page, can be censored; comments on campaign posts shared to the profiles of individuals are beyond the control of the original source. As demonstrated in Figure 4, the numbers of second-order comments were much higher on average for StrongerIn posts. This represents the first indication that the Stronger In campaign might have earned a higher level of pluralist debate.

Figure 4: First- and second-order commenting patterns by profile 23 January 2016-23 June 2017.

Table 2 shows the number and percentage of occurrences of words that can be attributed to our categories in the campaign posts. The first point to highlight is that all these pages were campaign-oriented, with the majority of categorized posts repeating slogans while attempting to mobilize their Facebook followers. Vote Leave was most campaign-oriented with 90 per cent of categorized posts included words related to campaigning; the next rival was Stronger In with 83 per cent of posts. Personalization was also used by both campaigns to give credibility to their arguments; Leave campaigns 
utilized public figures (for example entrepreneur James Dyson and former Head of the British Chamber of Commerce John Longworth as well as sports personalities Sol Campbell and Ian Botham and reality television star Joey Essex). Remain campaigns drew on expert opinion (including entrepreneur and TV personality Karren Brady, physicist Prof. Stephen Hawking and Bank of England Governor Mark Carney). Personalization also stretched to negative posts however. Leave campaigns questioned the motives for endorsing Remain: Vote Leave asked: 'are they doing it for a knighthood'. David Cameron also came under fire for his perceived failure to negotiate a better deal for the United Kingdom in the EU and then his support for Remain; the 'dodgy Dave' moniker was frequently used to undermine his personal credibility. There was also evidence of discrete political agendas however. The category that featured prominently, and almost uniquely on Leave campaign pages were references to sovereignty, often featuring the slogan 'Take Back Control'; immigration was also an area that was more prominent in the posts on Leave pages referring to various threats from EU expansion (Turkey, Albania and Macedonia being referenced) as well as the threat of Islamist extremists disguising themselves as refugees. A significant number of Leave campaign posts would show a picture or video, some referencing media reports, a simple argument relating to one of these latter issues and the Take Back Control slogan. The meme style-adopted suggests these posts were designed to be engaging and shareable and so extend reach and frame wider debates. Leave EU's page also combined policy messages with campaigning slogans and calls to action in particular combining a campaigning message when debunking the economic case for remaining (14\% of categorized posts) and with their sovereignty-related arguments (12\%). Vote Leave had a 
similar if more pronounced structure with campaign-focused sovereignty posts at $23 \%$ and personality-focused sovereignty posts at $14 \%$. The prominence of personalities as both advocates of the Leave position as well as targets for attacks indicates that this unofficial campaign pursued a more controversial and attacking stance as well as promoting its key spokesperson Nigel Farage.

Stronger In posts largely promoted the economic argument at the heart of the Remain case with 39 per cent of categorized posts being campaign posts about the economy and 16 per cent being personality-focused economic messages mainly including an expert quote. Lets Stay In Europe, while largely inactive, played the role of attack dog producing personality-focused attacks and memes with words categorized as personality and blame related often co-occurring with campaign messages and an economic argument. Many of these posts were direct attacks on Leave arguments, requesting supporters to share if they agreed the Leave case is ‘spurious', 'lies’ or 'rubbish'.

Table 2: The campaign strategies and agendas demonstrated in Facebook posts (No. and as percentage)

\begin{tabular}{|l|l|l|l|l|}
\hline & LeaveEU & VoteLeave & StrongerIn & LetsStayInEurope \\
\hline Campaign & $575(64 \%)$ & $668(87 \%)$ & $325(83 \%)$ & $19(66 \%)$ \\
\hline Personality & $364(41 \%)$ & $281(37 \%)$ & $160(41 \%)$ & $15(52 \%)$ \\
\hline Economy & $361(40 \%)$ & $150(20 \%)$ & $263(67 \%)$ & $12(41 \%)$ \\
\hline Sovereignty & $290(32 \%)$ & $269(35 \%)$ & $35(9 \%)$ & $3(10 \%)$ \\
\hline Immigration & $150(17 \%)$ & $154(20 \%)$ & $41(10 \%)$ & $1(3 \%)$ \\
\hline Blame & $153(17 \%)$ & $56(7 \%)$ & $42(11 \%)$ & $6(21 \%)$ \\
\hline Security & $51(6 \%)$ & $36(5 \%)$ & $38(10 \%)$ & $4(14 \%)$ \\
\hline
\end{tabular}

Comment patterns are an indication of at least interest in the content of a post. For Leave followers, negativity proved most popular. Posts containing negative language and attributing blame attracted just over 25 per cent more commentators than posts of any 
other category. Personal attack posts were most popular on the Leave EU page; political attacks focusing on Remain's economic arguments gained most comments from Vote Leave followers. A good example is a hyperlinked news article claiming 'Leaving the EU may trigger WWIII: Cameron says', LeaveEU posted this as 'another spurious claim from Dodgy Dave', subscribers responded with simple negative remarks such as 'lying bastard' and worse. These findings indicate the Leave community adhered to the dynamics of an echo chamber where Leave arguments were celebrated while Remainers were criticized and condemned. The veracity of Remain experts' claims were a particular target for commenters, one of the more polite rebuttals is captured in this response: '(Karren) Brady is a millionaire, given jobs by Tories, what's she know about people not getting hospital beds or houses because of immigrants coming here. Bet she was offered a gong for this'. In contrast, Botham and Essex were celebrated by commenters as being intouch, ordinary and so understanding the concerns and plight of 'normal' people. ProLeave entrepreneurs Dyson and Wetherspoon pub chain owner Tim Martin were hailed for not toeing the government line; their non-elitism applauded while experts were denounced as part of the elite.

Policy posts seldom generated many comments among Leave followers, and only if the focus was to attack an opponent. The only exception was when VoteLeave posted policy-related arguments from Nigel Farage, these gained numerous shares as well as messages of agreement. This contrasts with commenting patterns among StrongerIn followers. They were most likely to engage with posts on the topic of sovereignty; sometimes these were expressions of agreement with an attack against the Leave campaign, but at other points, there was a greater degree of pluralist debate. Commenters 
at points showed agreement with the Leave campaign's fundamental point; the string of comments following from these posts would conclude on the point that the United Kingdom was better off remaining an EU member, but commenters were prone to demonstrate was a degree of uncertainty regarding the way the EU was structured and the impact the institutions had on the domestic policy of member states. Hence while they were quick to act as cheerleaders when StrongerIn attributed blame to opponents, with Farage and Boris Johnson emerging as particular hate figures, at points some followers appear unequivocal in giving support to the Remain campaign leadership. In particular, there was a dearth of support expressed towards David Cameron and George Osborne, economic arguments combined with campaign or personality attracted some degree of criticism and they were as prone to argue the threats were exaggerated as their opposite numbers in the Leave camp. The plurality of discourse perhaps indicates why the Remain Facebook campaign overall lacked the same dynamic commitment as that enjoyed by the Leave campaign where cheerleading behaviour was the norm.

High levels of discussion, where multiple commenters make multiple comments on posts, reinforce this finding. Whereas posts attributing blame received most commentators, they generated the least discussion, with each commentator simply leaving a single supportive remark. However when the StrongerIn campaign posted on immigration, a rare but still significant occurrence, these generated intense discussion among a small number of commenters. As intense discussion may indicate some element of pluralism, it is useful to look at the text in comment fields. The data show followers were somewhat divided on some of the points relating to open borders, raising concerns about free movement of people across the EU. The fact that the StrongerIn page 
generated more intense discussion, almost three times greater $(\sim 1.6$ against $\sim 0.5-0.6)$ than the two Leave campaigns, further suggests higher levels of disagreement on core issues. Similarly, while the majority of commenters were unique to a single page, around 12,000 commented on posts of all three most popular campaign pages (VoteLeave, StrongerIn and LeaveEU), 34,224 (11 per cent of all commenters) comment on posts of both any Leave and Remain campaign page posts. As these people commented most on Leave sites, in particular acting as cheerleaders, it is suggested that they contributed to the divergence of opinion on some issues. Intense discussion and disagreement with the campaign were less evident on Leave pages although some comments did express hostility to the campaign leaders and arguments. To sum, Remain pages owned the most commented and most intensely discussed posts; therefore, they are likely to have seen greater divergence of views, debate and trolling. Leave pages earned a broader spread of comments across all posts, mostly supportive, little debate occurred and the few attacks were simplistic and often personal. Hence, the style of discourse appears to mirror commitment levels with Remain page followers at points demonstrating fairly reserved support.

\section{Discussion}

The Facebook pages created by the official campaigns and their unofficial subsidiaries for the United Kingdom’s EU membership referendum were essentially campaigning pages. The tendency of all four campaigns was to focus on promoting their arguments using simple slogans, as well as personalizing their arguments, employing key campaign figures, experts or celebrities to reinforce claims or as a way of undermining opponents. Policy was secondary and followed the campaign agendas: StrongerIn and LetsStayIn 
focusing on the economy; VoteLeave and LeaveEU on immigration and sovereignty. The first key difference was that Leave campaign pages were created earlier and were more proactive communicators throughout. Leave page subscribers reciprocated, proving equally proactive and highly committed. They more frequently liked and shared page content, contributing to heightened visibility, as well as producing greater numbers of supportive comments across posts so acting as cheerleaders for the campaign.

Cheerleading was a particular feature around the Leave campaign's agenda. The almost universal homogeneity was due to the fact that Leave pages appeared to act as catch-all platforms for EU detractors; they reiterated longstanding Eurosceptic positions prevalent within media (Blumler 2016; Wring 2016), which already had traction among the anti-EU political community. The ideological homogeneity was not mirrored on Remain pages. While page subscribers appeared to enjoy making attacks on key Leave figures, aside from that they displayed a far greater divergence of views. In particular, when policy was the focus of debate, Remain pages attracted some intense discussions as well as more critical or balanced commentary from within their subscriber network.

Three factors may explain this that can provide indications about how reading social media platforms can help to understand social dynamics around controversial issues. Firstly, the voter demographics for the two sides may be mirrored within the Facebook communities. Leave voters tended to have lower engagement levels, lower educational attainment and so would be less critical citizens (Goodwin and Heath 2016b), in contrast the better educated and informed Remain voters would have a more critical perspective and so be able to offer more balanced arguments, debate points as well as recognizing flaws within a campaign. The characteristics of each voter segment may have 
been replicated within the Facebook communities and so led one to act as cheerleaders while the others had a greater propensity to debate the issues. The greater criticality of Remain subscribers may have further shaped the dynamics within the page. While the social norm for Leave subscribers was to offer uncritical support, Remain subscribers could have been encouraged to be more critical, of the campaign, the 'project fear' style of messages as well as raising important questions regarding the United Kingdom's membership. While subscribers supported the United Kingdom remaining an EU member, this was often 'on balance'. This mood may have fostered greater criticality. These findings suggest that campaign dynamics are largely exogenous to a social media platform, but that importantly by studying the dynamics of discourse and argumentation on social media academics and campaigners can assess the mood and adjust their understandings of broader social attitudes and their formation and construction.

However, this overlooks campaign dynamics that are purely endogenous to a platform. The Leave page posts tended to be simplistic, campaigning, often attacking but reinforcing a well-established Eurosceptic trope. The Remain campaign offline and online has been shown as having been deficient in making an engaging and persuasive case that countered the core Leave case (Hughes 2016). The campaign, dubbed 'project fear', failed to change attitudes, and the replication of these messages on Facebook may have encouraged a more critical mood to take hold among subscribers. The scale of the supporter communities enjoyed by the three larger campaigns perhaps leads to the conclusion that all three factors are likely to have shaped the vibrancy of engagement and dynamics of commenting within each page. Demographic differences may have led to norms of behaviour emerging which then shaped the behaviour of newly joining or 
engaging subscribers who were encouraged to cheerlead on Leave pages or think more critically about issues if they subscribed to Remain. The campaigns, in turn, engaged supporters to differing degrees and equally encouraged divergent forms of engagement. Given the closeness of the result, it is possible firstly that the Leave campaigns' heightened visibility may have swung some late deciders into that camp. Secondly, the more critical and balanced views of Remain subscribers may have softened the position of some who may have started off with a clear perspective but could have been led to doubt their judgment. Hence, the Facebook communities may allow insights into the broader dynamics of the campaign and replicate conversations that may have occurred in the third places that allow face-to-face interaction. The divergences of opinions found in the Remain communities may also underline a lack of unreserved commitment and so explain the lower energy the campaign enjoyed and why in the end at the last moment more votes were cast for Leave than Remain.

Hence, we might argue that studying the Brexit camps on Facebook offers insights into wider societal dynamics that are perhaps encouraged as well as made visible by social media. Certainly it suggests academics and social analysts can gain insights into the dynamics of attitudes and beliefs that persist within a given group (Anstead and O’Loughlin 2015) at a minimum. However, research that aggregates big data has limitations, even when attempts are made to validate assumptions through hand coding. More innovative research among Facebook users, in particular members of political or campaign-oriented communities, is required to gain an understanding of what factors determine behaviours. The data do however allow us to make assumptions that have face validity based on research into the campaign (Jackson et al. 2016) and internal validity 
due to the qualitative exploration of the discourse. We can see that two camps came together around the campaign, and the camps reflected many of the characteristics of tribal political communities, such as their propensity to mock and attack opponents. But the camps also established different norms of behaviour, one unquestioning, one critical, suggesting that these and many similar Facebook camps actually represent in microcosm the wider political communities from which they are drawn.

\section{References}

Angus, D., Rintel, S. and Wiles, J. (2013), 'Making sense of big text: a visual-first approach for analysing text data using Leximancer and Discursis’, International Journal of Social Research Methodology, 16:3, pp. 261-67.

Anstead, N. and O’Loughlin, B. (2015), 'Social media analysis and public opinion: The 2010 UK general election', Journal of Computer-Mediated Communication, 20:2, pp. 204-20.

Blumler, J. (2016), ‘EEC/EU campaigning in long-term perspective’, in D. Jackson, E. Thorsen and D. Wring (eds), EU Referendum Analysis 2016: Media Voters and the Campaign, Bournemouth: CSJCC, p. 11.

Bogdanor, V. (2016), ‘A new way back for social democracy?: The EU referendum and its lessons for the left', Juncture, 23:1, pp. 8-11.

Bonacci, D., Jelinić, A., Jurišić, J. and Alujević-Vesnić, L. (2016), ‘Quantifying and comparing web news portals' article salience using the Vox Populi tool', 1st International Conference on Advanced Research Methods and Analytics. Valencia, Spain, July $6-7$. 
Campbell, V. and Lee, B. (2016), 'Party branding: A case study of online political posters', in D. G. Lilleker and M. Pack (eds), Political Marketing and the 2015 UK General Election, London: Palgrave, pp. 49-66.

Ceron, A., Curini, L., Iacus, S. M. and Porro, G. (2014), 'Every tweet counts? How sentiment analysis of social media can improve our knowledge of citizens’ political preferences with an application to Italy and France', New Media \& Society, 16:2, pp. 340-58.

Cvijikj, I. P. and Michahelles, F. (2013), 'Online engagement factors on Facebook brand pages’, Social Network Analysis and Mining, 3:4, pp. 843-61.

Gibson, R. and Cantijoch, M. (2013), 'Conceptualizing and measuring participation in the age of the Internet: Is online political engagement really different to offline?', The Journal of Politics, 75:3, pp. 701-16.

Goodwin, M. J. and Heath, O. (2016a), 'A tale of two countries: Brexit and the "left behind” thesis', LSE European Politics and Policy (EUROPP) Blog, 27 July, http://eprints.lse.ac.uk/70364/. Accessed 30 July 2017

_ (2016b), 'The 2016 referendum, brexit and the left behind: An aggregate-level analysis of the result', The Political Quarterly, 87:3, pp. 323-32.

Graber, D. (2003), 'The media and democracy: Beyond myths and stereotypes', Annual Review of Political Science, 6:1, pp. 139-60.

Graham, T., Jackson, D. and Wright, S. (2015), ‘From everyday conversation to political action: Talking austerity in online “third spaces”', European Journal of Communication, 30:6, pp. 648-65. 
Gunitsky, S. (2015), 'Corrupting the cyber-commons: Social media as a tool of autocratic stability', Perspectives on Politics, 13:1, pp. 42-54.

Hughes, K. (2016), 'Neither tackling lies or making the case: The remain side', in D. Jackson, E. Thorsen and D. Wring (eds), EU Referendum Analysis 2016: Media Voters and the Campaign, Bournemouth: CSJCC, p. 65.

Jackson, D., Scullion, R. and Molesworth, M. (2013), ‘15 “Ooh, politics. You’re brave”. Politics in everyday talk’, in R. Scullion, R. Gerodimos, D. Jackson and D. G. Lilleker (eds), The Media, Political Participation and Empowerment, London: Routledge, pp. 205-19.

Jackson, D., Thorsen, E. and Wring, D. (2016), EU Referendum Analysis 2016: Media Voters and the Campaign, Bournemouth: CSJCC

Jackson, N. A. and Lilleker, D. G. (2009), 'Building an architecture of participation? Political parties and Web 2.0 in Britain', Journal of Information Technology \& Politics, 6:3\&4, pp. 232-50.

Jungherr, A. (2015), Analyzing Political Communication with Digital Trace Data, Cham: Springer.

Koc-Michalska, K., Lilleker, D. and Vedel, T. (2016), 'Civic political engagement and social change in the new digital age’, New Media and Society, 18:9, pp. 1807-16.

Laver, M., Benoit, K. and Garry, J. (2003), ‘Extracting policy positions from political texts using words as data', American Political Science Review, 97:2, pp. 311-31.

Lilleker, D. G. and Jackson, D. (2017), 'The social media campaign: Persuasion and mobilisation', in D. Wring, R. Mortimore and S. Atkinson (eds), Political 
Communication in Britain: Polling, Campaigning and Media in the 2015 General Election, London: Palgrave, pp. 293-314.

Lilleker, D. G. and Koc-Michalska, K. (2017), 'What drives political participation? Motivations and mobilization in a digital age', Political Communication, 34:1, pp. 21-43.

Papacharissi, Z. (2002), ‘The virtual sphere: The internet as a public sphere’, New Media \& Society, 4:1, pp. 9-27.

Vraga, E. K., Thorson, K., Kligler-Vilenchik, N., \& Gee, E. (2015). How individual sensitivities to disagreement shape youth political expression on Facebook. Computers in Human Behavior, 45, 281-289.

Warren, M. E., \& Gastil, J. (2015). Can deliberative minipublics address the cognitive challenges of democratic citizenship?. The Journal of Politics, 77(2), 562-574.

Wojcieszak, M. E. and Mutz, D. C. (2009), 'Online groups and political discourse: Do online discussion spaces facilitate exposure to political disagreement?', Journal of Communication, 59:1, pp. 40-56.

Wright, S., Graham, T. and Jackson, D. (2016), ‘Third space, social media and everyday political talk’, in A. Bruns, G. Enli, E. Skogerbo, A. O. Larsson and C. Christensen (eds), The Routledge Companion to Social Media and Politics, New York: Taylor \& Francis, pp. 74-88.

Wring, D. (2016), ‘From super-market to Orwellian super-state: The origins and growth of newspaper scepticism', in D. Jackson, E. Thorsen and D. Wring (eds), EU Referendum Analysis 2016: Media Voters and the Campaign, Bournemouth: CSJCC, pp. 12-13. 
Zhu, Q., Skoric, M. and Shen, F. (2017), 'I shield myself from thee: Selective avoidance on social media during political protests', Political Communication, 34:1, pp. $112-31$.

Darren G. Lilleker and Duje Bonacci have asserted their rights under the Copyright, Designs and Patents Act, 1988, to be identified as the authors of this work in the format that was submitted to Intellect Ltd. 